\title{
Assessment of Fine and Coarse Sewage Sludge Ashes for Their Potential Use in Civil Engineering
}

\author{
Mamoudou Sall ${ }^{1, ~ *}$, Prince Momar Gueye ${ }^{2}$, Alassane Traoré ${ }^{3}$, Saliou Diouf ${ }^{1}$, Mouhamadou Sy ${ }^{4,5}$, \\ Guillaume Bouchez ${ }^{4}$, Abdou Ciss Wade ${ }^{1}$, Mamadou Lamine Sané3 ${ }^{3}$, Gora Dieye ${ }^{1}$, Djibril Diop ${ }^{1}$ \\ ${ }^{1}$ Laboratory of X-ray, Department of Physics, Cheikh Anta Diop University, Dakar, Senegal \\ ${ }^{2}$ Laboratory of Civil Engineering Materials, Polytechnic School of Dakar, Cheikh Anta Diop University, Dakar, Senegal \\ ${ }^{3}$ Institute of Applied Nuclear Technology, Cheikh Anta Diop University, Dakar, Senegal \\ ${ }^{4}$ GEMaC laboratory, University of Paris-Saclay, UMR UVSQ / CNRS, Versailles, France \\ ${ }^{5}$ Assane Seck University, UFR of Sciences and Technologies, Department of Physics, Ziguinchor, Senegal
}

Email address:

basall13@yahoo.fr (M. Sall)

${ }^{*}$ Corresponding author

\section{To cite this article:}

Mamoudou Sall, Prince Momar Gueye, Alassane Traoré, Saliou Diouf, Mouhamadou Sy, Guillaume Bouchez, Abdou Ciss Wade, Mamadou Lamine Sané, Gora Dieye, Djibril Diop. Assessment of Fine and Coarse Sewage Sludge Ashes for Their Potential Use in Civil Engineering. Journal of Civil, Construction and Environmental Engineering. Vol. 5, No. 4, 2020, pp. 84-91. doi: 10.11648/j.jccee.20200504.13

Received: July 29, 2020; Accepted: August 10,2020; Published: August 18, 2020

\begin{abstract}
New environmental challenges and research opportunities arise on the use of solid wastes as well as their basic properties. In fact, recycling of these wastes and their by-products is attracting increasing interest worldwide because of the high environmental impact in the cement, concrete and other industries. Two types (type1: Fa100 and type 2: Ba100) of sludge ashes from the sludge waste center of Camberene (Senegal) were combined with different proportions of lime to assess their potential use in civil engineering. XRF, optical microscopy and spectroscopy were used to characterize the samples. The following major elements are present in the ashes: $\mathrm{SiO}_{2}, \mathrm{Al}_{2} \mathrm{O}_{3}, \mathrm{Fe}_{2} \mathrm{O}_{3}, \mathrm{CaO}, \mathrm{P}_{2} \mathrm{O}_{5}$. For the minor elements their concentration are very important in type 1 compared to those in type 2 . These ashes have similar composition with cement except for $\mathrm{CaO}$. The measurement of absorbance on the ashes shows a clear difference in optical absorption between samples. The lime pellet transmits more compared to $\mathrm{Ba} 100$ and Fa100 pellets. The materials obtained by mixing ash with lime in various proportions have a lower optical transmission with respect to lime and ash taken separately. Thus, the designed materials transmit less light which suggests an improved thermal isolation. The studied ashes suggest that they are not dangerous based on the Annex III of (criterion H14 of Directive 91 / 689 / EEC).
\end{abstract}

Keywords: Sewage Sludge Ash, Lime, XRF, Optical Microscopy and Spectroscopy

\section{Introduction}

The very high price of cement, the increasing demand for energy as well as the contribution to climate change by greenhouse gases $(\mathrm{GHG})$ emissions in the atmosphere (CO2 in particular) which are around $7 \%$ from cement manufacturing is partly responsible for global warming.

$[1,2]$. Disposal and treatment of hazardous waste is expensive for industry. The production of sewage sludge (SS) for the United States of America (USA) of dry solids per year is $7 \mathrm{Mt}$ while the European one $[3,4]$ was estimated to be 10 Mt in 2012. These sewage sludge are managed between incineration, agricultural and landfill $[5,6]$. It is found that the incineration processes reduce the volume of the waste by $90 \%$ and its mass by $70 \%$, the potential production of sewage sludge ash (SSA) would be about $3 \mathrm{Mt}$ [7]. In 2012, Germany, France and the Netherlands have generated $0.7 \mathrm{Mt}$ of SSA by incineration of $2.3 \mathrm{Mt}$ of SS. This amount is increasing because of a decrease in the agriculture disposal option due to the presence of heavy metals and pathogenic agents and the increase in price for landfilling $[8,9]$.

Indeed these wastes contaminate the soil through the discharge of oil and other chemicals, and also affect the quality of surface water and groundwater [10]. The 
incineration process is the most appropriate management option to deal with the volumes produced and the potentially unsafe elements the sewage sludge contains [7]. The coincineration of SS with coal as supplementary fuel in cement kilns, power plants and brick kilns has been proposed in some countries (China, Cyprus, Spain) [11].

It was found in some earlier work that the sewage sludge ashes may possess pozzolanic properties, allowing them to be used in blended Portland cements [12]. However, more recent work has revealed that ashes possess very little if any pozzolanic activity [13], even when the ashes were milled to a high degree of fineness [7, 14]. Lynn and al [7] did the compendium of some data based on a total of 156 publications, dating from 1983-2015 and originating in 30 countries across Europe (72 publications), Asia (65), North America (11), South America (4), Africa (3) and Australia (1), with the largest contributions from Taiwan (27 publications), UK (19), Spain (17) and Japan (16). This shows that the data has been published over a period of 26 years and the majority of the research has been undertaken in the last 10 years, though as a sign of growing interest in the use of sustainable materials. In their paper the physical and chemical characteristics of SSA and its use as raw feed for cement clinker and as components in producing cement paste, mortar and concrete mixture, as well as fine, filler and manufactured lightweight aggregates were investigated.

Sludge ash is very interesting for many applications because it can be mixed with cement or binders such as lime to give rise to new materials with several attractive physical characteristics such as the increase in resilience, the longterm strength of mortars $[5,7,15]$. Their mechanical properties open industrial perspectives for the manufacture of cement and building at lower cost with some ecological contribution. In fact, new environmental challenges and research opportunities arise on the use of these solid wastes as well as their basic properties. Recycling of these wastes and their by-products is attracting increasing interest worldwide because of the high environmental impact in the cement, concrete and other industries. For example, lightweight concrete can be made from industrial by-products and hazardous solid wastes such as fly ash, sewage sludge ash, bottom ash, slag, etc. Cement can be replaced by 15 to $35 \%$ by this waste without significantly affecting the properties of the material obtained [10]. In some studies, replacing cement with $10 \%$ or $20 \%$ ash from sewage sludge shows an increase in setting time due to the significant presence of phosphorus in sludge ash [16]. Similarly, the compressive strength of the mortars was lower than that of the reference mortar consisting solely of cement [17]. In fact, the addition of these ashes slows down the kinetics of resistance development; however, the long-term strength of the mortar with addition was greater than that of the reference mortar [16]. In the literature, it is reported that these additions can improve sulphate concrete's strength, workability, and also decrease permeability [10]. It has been observed that the characteristics of ash from sewage sludge are similar to those of ceramics. Their use in ceramics applications for bricks, tiles and ceramic glass considerably improves these materials by densifying them, increasing their strengths [18]. Ceramic panes with ash additions have achieved higher resistances than natural materials such as granite and marble with strong durability properties [7].

The strength activity index (SAI) value of SSA was smaller than that of fly ash, the effectiveness of using SSA in mortar was lesser than that of fly ash [19]. Moreover, the water demand of SSA mortar is higher than that of ordinary cement mortar. Pan [20] found that the addition of SSA affected the mortar workability. This phenomenon is primarily due to the porous and irregular morphology of SSA Consequently, it is difficult to adequately maintain water-tocement ratio and workability of SSA mortar simultaneously. The application of mechanical grinding to adjust SSA fineness was an effective modification to improve SSA mortar properties [15].

Regarding the problems related to the cost of construction in the building, air pollution such as greenhouse gases and energy expenditure for the production of cement, we propose to study the effect of the integration of the ashes of Sewage treatment plant (STEP) in lime, to produce an environmentally-friendly cement. Indeed, lime can react with silica in the presence of water to produce a hydrated calcium silicate responsible for the resistance of cementitious materials. Since wastewater treatment plants produce large amounts of solid waste such as STEP ashes, they can be recovered and be used as building materials $[3,5,10,16]$.

A chemical characterization by X-ray fluorescence as well as an optical study by microscopy and by spectroscopy of our samples were conducted. In fact, X-ray fluorescence is one of the few techniques able to analyze samples non-destructively and in situ. It offers new possibilities for case analysis that cannot be satisfied by conventional techniques. To date, one of the most common applications has been the analysis of environmental samples, including industrial sites soils to study their contamination by heavy metal [21]. X-ray fluorescence is also used in ash characterization [2, 22, 23]. Among the many experimental methods used in the study of ash-based samples, optical microscopy and spectroscopy are non-destructive observation and analysis techniques with good spatial and temporal resolution. Optical microscopy allows us to monitor, spatially analyze in time and as a function of temperature the physical behavior of our samples and also to study the size distribution of the ashes. Optical spectroscopy allows us to track and determine transmission as a function of wavelengths from $200 \mathrm{~nm}$ to $2000 \mathrm{~nm}$.

\section{Materials and Methods}

\subsection{Origin of the Materials Used}

The sewage sludge ashes used in this work come from the Senegalese sewage treatment plant of Camberene located in the Dakar region. The sludge is dewatered, dried and burnt in a fluidized bed incinerator. Then we obtain two types of sewage sludge ashes: fine and coarse. 
Fine sludge ash has a gray color, is entrained by the combustion gases and is recovered during the purification

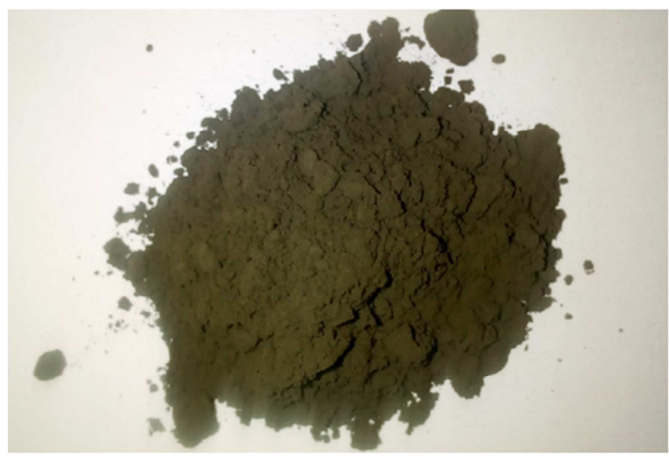

a while the coarse one has a black color and comes from the combustion chamber (Figure 1).

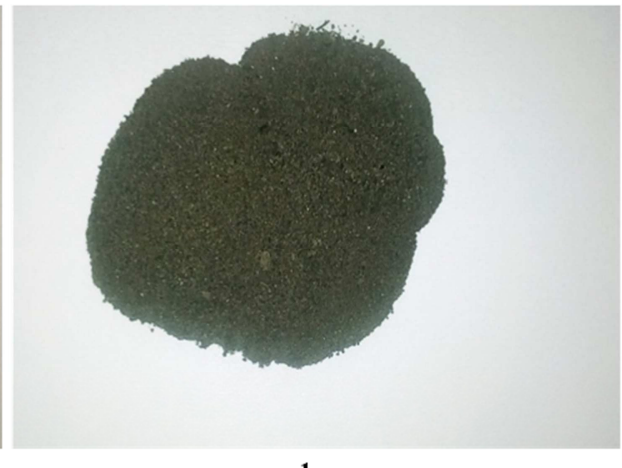

b

Figure 1. Fine ash sample (a) and coarse ash sample (b).

The fine ash, soft to the touch, is obtained from the incineration of sludge. It has an apparent density of 0.71 $\mathrm{g} / \mathrm{cm}^{3}$ and an absolute density of $2.4 \mathrm{~g} / \mathrm{cm}^{3}$ whereas the coarse ash has an absolute density and an apparent density of $2.1 \mathrm{~g} / \mathrm{cm}^{3}$ and $0.9 \mathrm{~g} / \mathrm{cm}^{3}$ respectively.

The lime, as an important material used in the building construction, has an apparent density varying between 0.6 and $0.75 \mathrm{~g} / \mathrm{cm}^{3}$ while its absolute density is in the range 2.6 and $2.9 \mathrm{~g} / \mathrm{cm}^{3}$.

\subsection{Analytical Procedures}

\subsubsection{XRF Chemical Characterization}

Samples were weighed and then introduced in oven at $105^{\circ} \mathrm{C}$ for $24 \mathrm{~h}$ to remove moisture prior to the preparation of pellets made by mixing them with $10 \mathrm{wt} \%$ of a binder called Licowax [24, 25].

We use several mixtures by combining sewage sludge ash and lime at different proportion (Table 1).
Table 1. Sewage sludge ash and lime at different proportion.

\begin{tabular}{ll}
\hline Mix combinations & Designation \\
\hline Fine sludge ash & FA100 \\
Coarse sludge ash & BA100 \\
Lime & CH100 \\
Fine sludge ash $+10 \mathrm{wt} \%$ de lime & CH10FA90 \\
Fine sludge ash $+20 \mathrm{wt} \%$ de lime & $\mathrm{CH} 20 \mathrm{FA} 90$ \\
Fine sludge ash $+30 \mathrm{wt} \%$ de lime & $\mathrm{CH} 30 \mathrm{FA} 90$ \\
Coarse sludge $a \mathrm{ash}+10 \mathrm{wt} \%$ de lime & $\mathrm{CH} 10 \mathrm{BA} 90$ \\
Coarse sludge ash $+20 \mathrm{wt} \%$ de lime & $\mathrm{CH} 20 \mathrm{BA} 80$ \\
Coarse sludge ash $+30 \mathrm{wt} \%$ de lime & $\mathrm{CH} 30 \mathrm{BA} 70$ \\
\hline
\end{tabular}

The obtained mixture was homogenized in a mortar and the technology press VANEOX FLUXANA considering a force of $10 \mathrm{~N}$ on a surface of a disk of a radius of $11 \mathrm{~mm}$ was used to form the pellets. After obtaining the pellets, we used an X-ray portable fluorescence Niton XLT900s (P-XRF) for our X-ray analyzes with a measurement time of $350 \mathrm{~s}$.

XRF was performed with $100 \%$ normalization and full fundamental parameter quantification techniques: see Table 2 for specification and operating conditions.

Table 2. Spectrometer specification and operating conditions.

\begin{tabular}{ll}
\hline Resolution & $\mathbf{1 7 8 e V}$ at $\mathbf{M n ~ K \boldsymbol { \alpha }}$ \\
\hline Window Thickness & $12.7 \mu \mathrm{m} \mathrm{Be}$ \\
Rating & $50 \mathrm{kV}, 40 \mu \mathrm{A}$ maximum power of the tube 2W \\
Beam diameter & $7 \mathrm{~mm}$ \\
Filter & Element analysis \\
Ag excitation source & $\mathrm{Sb}, \mathrm{Sn}, \mathrm{Cd}, \mathrm{Pd}, \mathrm{Ag}, \mathrm{Mo}, \mathrm{Nb}, \mathrm{Zr}, \mathrm{Sr}, \mathrm{Rh}, \mathrm{Bi}, \mathrm{As}, \mathrm{Se}, \mathrm{Au}, \mathrm{Pb}, \mathrm{W}, \mathrm{Zn}, \mathrm{Cu}, \mathrm{Re}, \mathrm{Ta}, \mathrm{Hf}, \mathrm{Ni}, \mathrm{Co}, \mathrm{Fe}, \mathrm{Mn}, \mathrm{Cr}, \mathrm{V}, \mathrm{Ti}, \mathrm{Th}, \mathrm{and} \mathrm{U}$ \\
Sandwich of Al, Ti and Mo & $\mathrm{Ba}, \mathrm{Sb}, \mathrm{Sn}, \mathrm{Cd}, \mathrm{Pd}, \mathrm{Ag}$ \\
Cu Filter & $\mathrm{Cr}, \mathrm{V}, \mathrm{Ti}, \mathrm{Ca}, \mathrm{K}$ \\
No Filter & $\mathrm{Al}, \mathrm{P}, \mathrm{Si}, \mathrm{Cl}, \mathrm{S}, \mathrm{Mg}$ \\
\hline
\end{tabular}

\subsubsection{Optical Characterization}

The optical absorption spectra were measured with the Ocean optics Inc S2000 spectrometer, which has been installed and combined with the color camera (DALSA Falcon 1.4M100 capable of capturing 100 frames per second) on the optical microscope (Nikon Eclipse LV100 POL can operate in illumination by reflection or transmission). The sample was enclosed in a cryogenic set based on a $4 \mathrm{~K}$ helium-flow cryostat system designed for optical microscopy (Microstat He with temperature controller ITC503/Oxford Instr.). The instrument is equipped with a specially designed sample cell, put in helium atmosphere so as to ensure a fast heat exchange and a good temperature homogeneity.

We used a Perkin Elmer LAMBDA 950 2-channel spectrophotometer equipped with transmission and reflection modules $\left(6^{\circ}\right.$ to $\left.68^{\circ}\right)$. This allowed us to measure the prepelletized optical transmission spectra with approximately $90 \%$ 
mass $\mathrm{KBr}$. With this setting the optical response of our samples according to the dilution between the ash and the lime can be followed and some physical parameters determined.

\section{Results and Discussion}

\subsection{X-ray Fluorescence Analysis (XRF)}

A portable XRF device Niton XLT900s was used to analyze the chemical composition of the sludge ashes in terms of major and minor elements. After XRF analysis of these ashes, we then calculated the major oxide composition using the following formulas (equations 1-6). Oxides are the major elements and are expressed in $\%$, while the minor elements are given in $\mathrm{mg} / \mathrm{kg}$.

$$
\begin{aligned}
& \% S_{i} O_{2}=\frac{\% S_{i}\left(A_{S i}+2 A_{O}\right)}{A_{S i}} \\
& \% A l_{2} O_{3}=\frac{\% A l\left(2 A l+3 A_{O}\right)}{A_{A l}} \\
& \% C_{a} O=\frac{\% C_{a}\left(A_{C a}+A_{O}\right)}{A_{C a}} \\
& \% M_{g} O=\frac{\% M_{g}\left(A_{M g}+A_{O}\right)}{A_{M g}}
\end{aligned}
$$

$$
\begin{gathered}
\% P_{2} O_{5}=\frac{\% P\left(2 A_{P}+5 A_{O}\right)}{A_{P}} \\
\% S O_{3}=\frac{\% S\left(A_{S}+3 A_{O}\right)}{A_{S}}
\end{gathered}
$$

In equations (1) to (6), A represents the atomic mass. The data obtained are presented in Table 3.

Table 3. Results of major (\%) and minor $(\mathrm{mg} / \mathrm{kg})$ elements using XRF technique of sewage sludge ash contents.

\begin{tabular}{|c|c|c|c|c|c|c|}
\hline Element & $\begin{array}{l}\text { Fly ash (type } 1 \\
\text { ash) PW }\end{array}$ & $\begin{array}{l}\text { (Martin Cyr, } \\
\text { 2007) }\end{array}$ & $\begin{array}{l}\text { (Nuria Husillos } \\
\text { Rodríguez, } 2013\end{array}$ & L. C Morais (2010) & $\begin{array}{l}\text { Siew Choo Chin } \\
(2016)\end{array}$ & $\begin{array}{l}\text { Bottom ash } \\
\text { (type } 2 \text { ash) PW }\end{array}$ \\
\hline $\mathrm{SiO}_{2}$ & 24.1 & 34.2 & 3.72 & 26.39 & 18.49 & 33.92 \\
\hline $\mathrm{Al}_{2} \mathrm{O}_{3}$ & 6.69 & 12.6 & 2.56 & 12.16 & 7.95 & 12.19 \\
\hline $\mathrm{Fe}_{2} \mathrm{O}_{3}$ & 12.6 & 4.7 & 7.58 & 5.92 & 14.44 & 8.58 \\
\hline $\mathrm{CaO}$ & 22.2 & 20.6 & 7.62 & 23.25 & 4.20 & 17.4 \\
\hline $\mathrm{MgO}$ & 3.90 & 1.9 & 0.60 & 14.11 & 0.91 & 1.80 \\
\hline $\mathrm{K}_{2} \mathrm{O}$ & 3.22 & 1.7 & 0.53 & 1.32 & 1.13 & 2.51 \\
\hline $\mathrm{MnO}$ & 0.10 & 0.06 & 0.05 & 0.11 & 0.09 & 0.07 \\
\hline $\mathrm{P}_{2} \mathrm{O}_{5}$ & 5.92 & 14.8 & 6.43 & 8.44 & 6.56 & 3.86 \\
\hline $\mathrm{Pb}$ & 357 & 720 & 40 & - & 30 & 66 \\
\hline $\mathrm{Cu}$ & 1264 & 2483 & 320 & - & 130 & 553 \\
\hline $\mathrm{Cr}$ & 212 & 2636 & 1270 & - & 20 & 67 \\
\hline $\mathrm{Zn}$ & 3632 & 7103 & 1020 & - & 810 & 1156 \\
\hline As & 16 & 23 & 5.8 & - & - & 6 \\
\hline
\end{tabular}

\begin{tabular}{lll}
\hline Elements & Fly ash (type1) & Bottom ash (type 2) \\
\hline $\mathrm{SiO}_{2}$ & 24.1 & 33.92 \\
$\mathrm{Al}_{2} \mathrm{O}_{3}$ & 6.69 & 12.19 \\
$\mathrm{Fe}_{2} \mathrm{O}_{3}$ & 12.6 & 8.58 \\
$\mathrm{CaO}$ & 22.2 & 17.4 \\
$\mathrm{MgO}$ & 3.90 & 1.80 \\
$\mathrm{~K} 2 \mathrm{O}$ & 3.22 & 2.51 \\
$\mathrm{TiO}_{2}$ & 0.66 & 0.51 \\
$\mathrm{MnO}$ & 0.10 & 0.07 \\
$\mathrm{P}_{2} \mathrm{O}_{5}$ & 5.92 & 3.86 \\
$\mathrm{~Pb}$ & 357 & 66 \\
$\mathrm{Cu}$ & 1264 & 553 \\
$\mathrm{Cr}$ & 212 & 67 \\
$\mathrm{Zn}$ & 3632 & 1156 \\
$\mathrm{As}$ & 16 & 6 \\
\hline
\end{tabular}

In Table 4 we resume studies from other authors in order to give a comparative asset in term of elemental composition with the samples we have used.

Table 4. Comparison of major (\%) and minor (mg/kg) element contents measured with other authors working with the same materials.

The high variability between values shows that sludge ashes depend on several parameters: sludge composition, treatment conditions such as incineration temperature and additives. The major elements concentrations in type 2 ash resemble to the sewage sludge ash in [17] except for $\mathrm{P}_{2} \mathrm{O}_{5}$ whose value is 3.86 in the former and 14.8 in the latter. In the same way the concentration of $\mathrm{Fe}_{2} \mathrm{O}_{3}$ is higher in type 2 ash. The minor elements are much less representative in our ashes when compared with those in Cyr's work [5]. However the concentration of $\mathrm{SiO}_{2}, \mathrm{Al}_{2} \mathrm{O}_{3}$ and $\mathrm{Fe}_{2} \mathrm{O}_{3}$ are similar to for both type 1 and sewage sludge ash in ref. [26] of Siew Choo Chin. The concentration of $\mathrm{CaO}$ in the former is instead four times higher than that in the latter. The similarity of these ashes with ours is important to highlight as they are both used in the processing of cement and concrete. Indeed, our ashes show some similarities with one type of cement in Senegal having the following chemical composition: $\mathrm{SiO}_{2}$ (19.53), $\mathrm{Al}_{2} \mathrm{O}_{3}$ (7.12), $\mathrm{Fe}_{2} \mathrm{O}_{3}$ (2.22), $\mathrm{CaO}$ (65.5). These suggest that the sewage sludge ashes presented in this work may be used in civil engineering. The histograms of the concentrations of these two ashes against the measured elements (major and minor) are plotted for comparison (Figure 2). We find that concentrations of $\mathrm{SiO}_{2}$ and $\mathrm{Al}_{2} \mathrm{O}_{3}$ are higher in bottom ash. As for heavy metals they are more important in fly ash than in bottom ash, this could be due to their volatility. For example, the concentration of $\mathrm{Pb}$ is about five times higher in fly ash than in bottom ash, while that of $\mathrm{Zn}$ is 3.5 times greater in fly ash than that of $\mathrm{Zn}$ in ash in the bottom ash. Analogous observations are also relayed by Rajamma [22], in their work on the characterization and use of biomass fly ash in cement 
based-materials. From the point of view of availability, bottom ash is more important than fly ash.

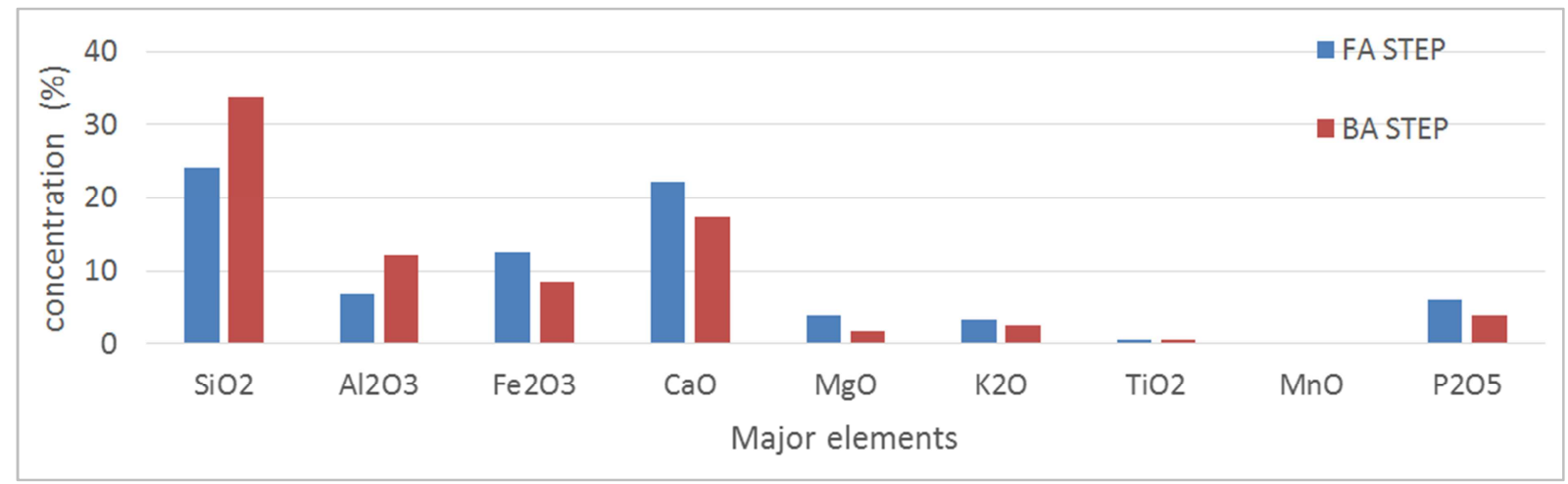

(a)

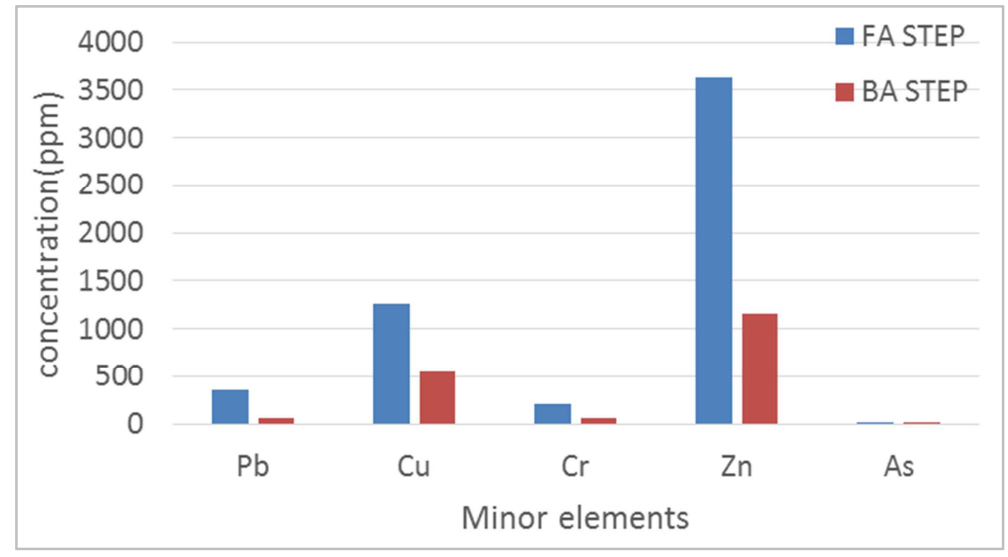

(b)

Figure 2. Chemical Composition in Major (a) and Minor Elements (b).

\subsection{Optical Microscopy and Optical Absorption Spectroscopy Analyses}

Optical microscopy combined with optical absorption spectroscopy, has allowed us to observe and measure the absorbance of the powdered samples, revealing a highly inhomogeneous ash particle size distribution for the Ba100 compound (Figures 4 and 5). The absorption and photospectroscopy measurements are performed respectively on powder samples and pellets, at ambient temperature and pressure, by using the same experimental setup. The transmitted light is injected by optical fiber in the spectrometer Ocean Optics 2000. At the start of the experiments, we first characterized the incident spectrum of

(a)
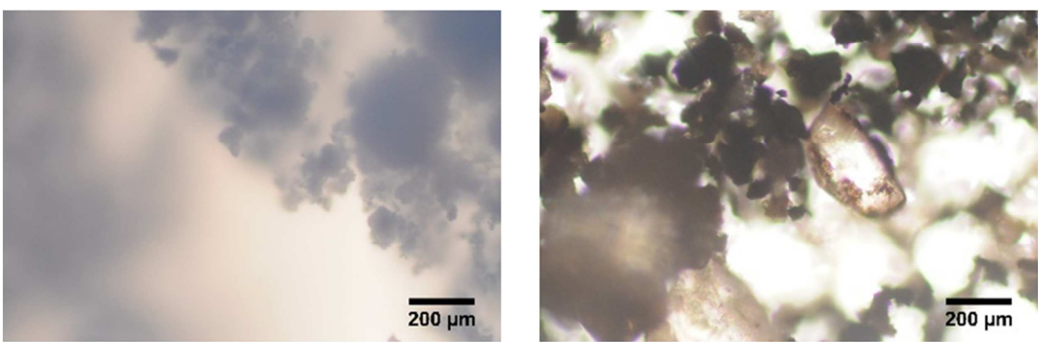

lamp injected directly to the detector of the USB spectrometer through the optical fiber [27]. The analysis of the absorbance spectra on the ashes shows the existence of a clear difference in optical absorption between samples, for example Fa100 and Ba100 ashes (Figure 5).

The absorbance $\log \frac{I_{0}}{I}$ (where $I_{0}$ is the incident intensity and $\mathrm{I}$ is the transmitted intensity) of Ba100 is greater than one while that of Fa100 is lesser than one. This means that in the visible light the number of particles absorbing in Ba100 is more important than that in Fa100. From the optical micrographs in Figure 3 it can be observed that the SSA has a porous structure and the particles size are in irregular shape, this influence the absorbance (Figures 4 and 5).

Figure 3. Optical microscope (objective of X20/NA=0.40) images of (a) lime, (b) Bal00 ash and (c) Fa100 ash. 


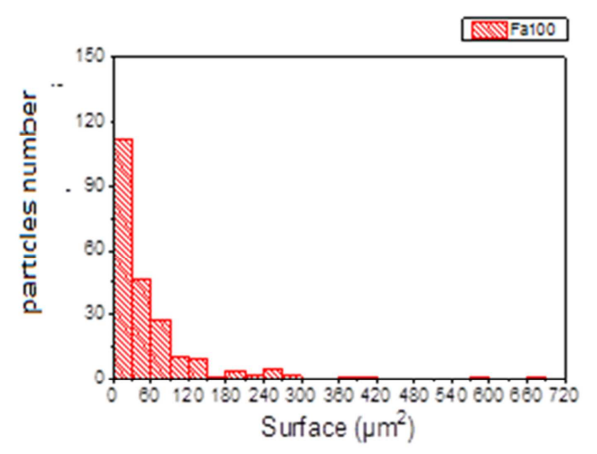

(a)

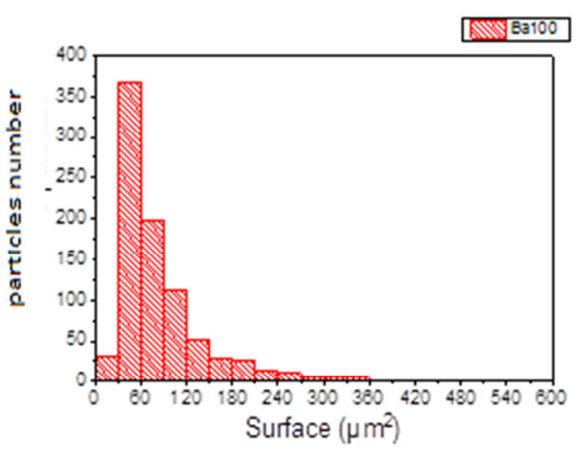

(b)

Figure 4. Particles size distribution of Fal00 ash (a) and Ba100 ash (b).

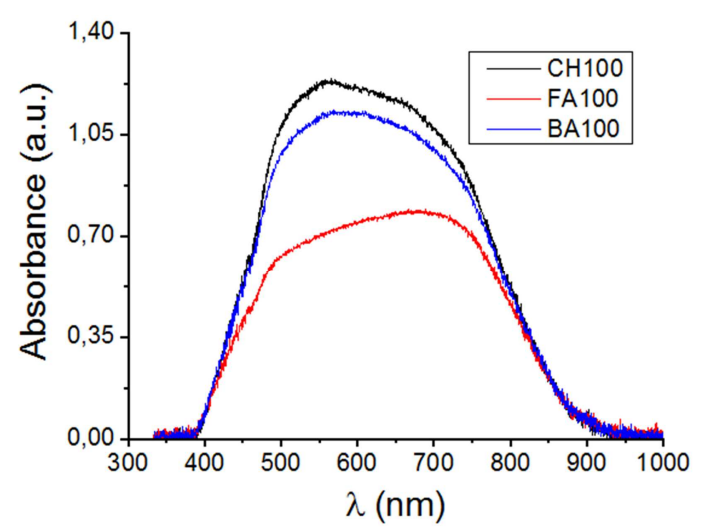

Figure 5. Absorbance spectra of lime powders (CH100), Fa100 and Ba100 sludge ashes.

The optical spectra in Figure 5 show differences in absorption bands in the visible region. The shape of the absorption edge depends on the particle size distribution. Hence the differences in the absorbance is due to the total number of large particles and the dark particles per unit surface being higher in BA100 than in FA100 compounds [28, 29].

The compounds $\mathrm{CH} 100$, Fa100, Ba100, studied by spectrophotometry, as shown in Figure 6, exhibit a nonlinear transmission behavior. The measurements show a high transmission in the infrared of $\mathrm{CH} 100$ but a low transmission for the others samples. The lime pellet transmits more compared to Ba100 and Fa100 pellets. The irregular particles shape of the SSA is believed to lower the transmission.

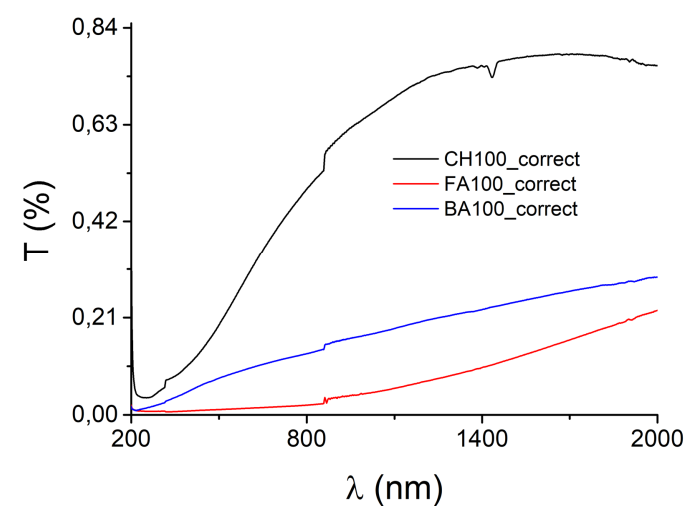

Figure 6. Transmission spectra of Fa100, Ba100 and CH100
When lime is added to the ashes, it is observed that the transmission increases with the percentage of lime added but always remains lower than that of the sample consisting only of ashes (FA100) (Figure 7a). However, for BA100, it can be seen that the highest transmission is obtained with CH20BA80 and the lowest with CH30BA70. The CH10BA90 lies in between (Figure 7b).
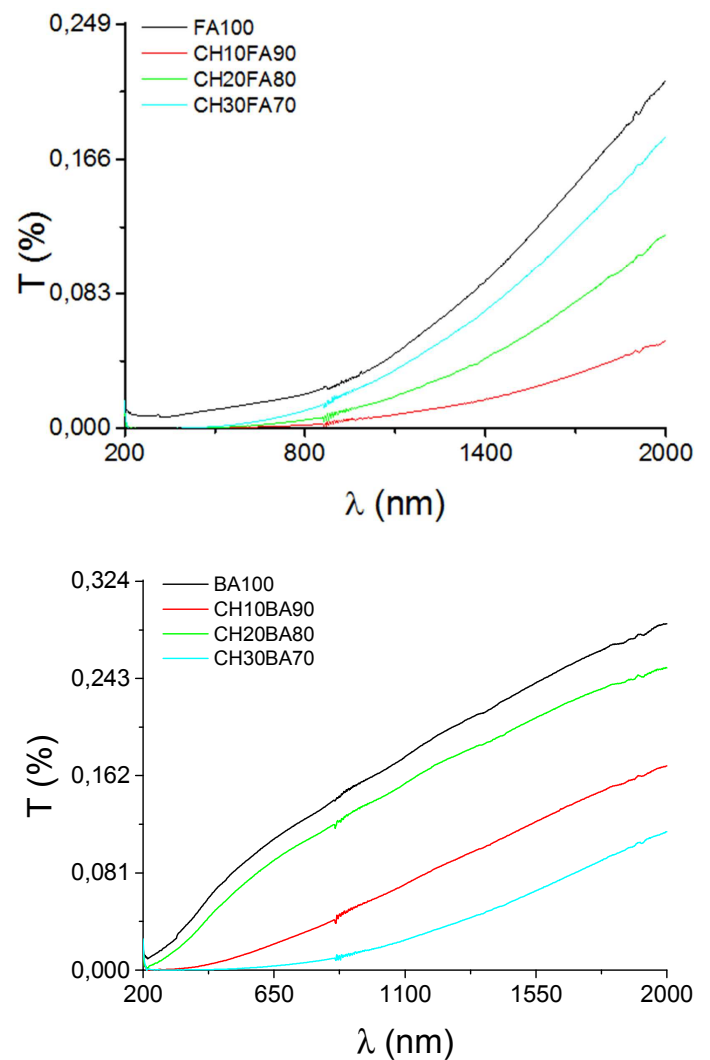

Figure 7. Transmission spectra of a) Fa100 and its corresponding mixtures and b) Ba100 and their corresponding mixtures.

This shows that the behavior of these two ashes mixed with lime in identical proportions is not the same. This is in agreement with results obtained by optical microscopy. When the percentage of added lime is less than $20 \%$, BA samples have a higher transmission than those of FA. Beyond that, the opposite is observed.

In the field of construction, to have materials with thermal 
insulation, a low coefficient of thermal transmission is required. So, the weaker the transmission, the better the thermal insulation. In the present work, optical transmission defined by $I / I_{0}$ ( $I$ is the intensity transmitted by the sample surface and $I_{0}$ is the incident intensity) was used to simulate the thermal properties of the materials. The idea being to analyze the effect of transmittance when lime is added to sewage sludge ashes. The materials obtained by mixing ash with lime in various proportions have a lower optical transmission with respect to lime and ash taken separately (Figure 7). Thus the designed materials transmit less light which suggests an improved thermal isolation. For the fine ash the weakest transmission is observed for CH10FA90 while for bottom ash it is CH30BA70. These two ashes do not have the same optical behavior when mixed with lime.

\section{Toxicological Risk}

The possible dangerousness of the ash from STEP sludge depends essentially on their heavy metal content with regard to the limits of regulated hazardous substances on one hand, and on the other hand on the overall ecotoxicity of the ash (criterion H14 of Directive 91 / 689 / EEC).

In this Directive the material is toxic if its content in heavy metal is higher to some thresholds as defined in Annex III (Table 5).

Table 5. Comparison of the concentration of minor elements in ashes with thresholds defined in Annex-III.

\begin{tabular}{llll}
\hline Element & Concentration (mg/kg) type 1 ash & Concentration (mg/kg) type 2 ash & Threshold concentration (mg/kg) \\
\hline $\mathrm{As}$ & 16 & 6 & 220 \\
$\mathrm{Cr}$ & 212 & 67 & 150 \\
$\mathrm{Cu}$ & 1264 & 553 & 340 \\
$\mathrm{~Pb}$ & 357 & 66 & 840 \\
\hline
\end{tabular}

In most of cases, the heavy metal contents of these ashes are below the threshold concentration in Table 5, so the ashes cannot therefore be a priori considered dangerous on the basis of these criteria. The classification of ashes can vary according to the criteria used, depending on the geographic location as well. However some researchers differ on the definition of toxicity of ashes. Some will put them in landfill if there are considered dangerous while some others who consider them non dangerous will value them.

Thus a study of the dangerousness of the ash is necessary in order to see their possible compatibility with the recovery in construction.

\section{Conclusion}

The potential use of fine and coarse sewage sludge ash in civil engineering was investigated.

Both ashes and mixtures have been characterized:

Most of the chemical elements in the samples are in compliance with cement contents except for $\mathrm{CaO}$, which is found to be less important. This is suggesting that these ashes can be used in ceramic materials, cement and concrete.

The lime pellet transmits more compared to Ba100 and Fa100 pellets. The transmission increases with the percentage of lime added but always remains lower than that of the sample consisting only of ashes (FA100). For BA100, it can be seen that the highest transmission is obtained with CH20BA80 and the lowest with CH30BA70.

Thus the designed materials transmit less light suggesting an improved thermal isolation. The measurement of the absorbance on the ashes shows the existence of a clear difference in optical absorption between the samples. The heavy metal contents of these ashes are below the threshold in Annex III of (criterion H14 of Directive 91 / 689 / EEC) indicating their non-dangerousness. As perspective, other complementary techniques such as X-ray diffraction will be used to assess the formation of new phases before and after hydration. Similarly, other basic knowledge about dimensional stability, compressive strengh, density, thermal properties and water demand should be investigated.

\section{Conflicts of Interest}

All the authors do not have any possible conflicts of interest.

\section{Acknowledgements}

The authors would acknowledge P2MC team from GEMaC Laboratory (University of Paris-Saclay / University of Versailles Saint-Quentin UMR UVSQ / CNRS) for the technical assistance with the optical spectrophotometry measurements, as well as Institute of Applied Nuclear Technology, Department of Physics, Faculty of Sciences and Techniques, University of Cheikh Anta Diop, Dakar, Senegal for helping with the XRF.

\section{References}

[1] F. FROHARD, «Durability of green concretes: impact of alternative cementitious materials on the corrosion of steel in reinforced concrete», Université Paris-Est, 2014, p.

[2] M. Chen; D. Blanc; M. Gautier; J. Mehu R. Gourdon, «Environmental and technical assessments of the potential utilization of sewage sludge ashes (SSAs) as secondary raw materials in construction». Waste Manag, 33, 2013. p. 126875 .

[3] OECD, «Organization for economic co-operation and development»: https://data.oecd.org/fr/, 2017, p.

[4] EUROSTAT, «Sewage sludge production and disposal from wastewater treatment plant parameters»: https://appsso.eurostat.ec.europa.eu/nui/show.do?dataset=env ww_spd\&lang=en», 2020, p. 
[5] M. Cyr, G. Klysz, S. Julien, P. Clastres, Les cendres d'incinération de Stations de Traitement des Eaux Polluées (STEP) sont-elles utilisables dans les matrices cimentaires? Comparaison avec les cendres volantes de charbon, Déchets Sciences et Techniques 29 (2003) 22-29.

[6] EUROSTAT, http://epp.eurostat.cec.eu.int, 2005.

[7] C. J. Lynn; R. K. Dhir; G. S. Ghataora R. P. West, «Sewage sludge ash characteristics and potential for use in concrete». Construction and Building Materials, 98, 2015. p. 767-779.

[8] P. Stasta; J. Boran; L. Bebar; P. Stehlik J. Oral, «Thermal processing of sewage sludge». Applied Thermal Engineering, 26, 2006. p. 1420-1426.

[9] J. Payá; J. Monzó; M. V. Borrachero L. Soriano, «Sewage sludge ash», in New Trends in Eco-efficient and Recycled Concrete, 2019. p. 121-152.

[10] S. Badur, R. Chaudhary, «Utilization of hazardous wastes and by-products as a green concrete material through $\mathrm{S} / \mathrm{S}$ process: A review». Rev. Adv. Mater. Sci, 17, 2008. p. 42-61.

[11] G. Zhang; J. Hai; J. Cheng; Z. Cai; M. Ren; S. Zhang J. Zhang, « Evaluation of PCDD/Fs and metals emission from a circulating fluidized bed incinerator co-combusting sewage sludge with coal ». Journal of Environmental Sciences, 25, 2013. p. $231-235$.

[12] J. Monzó; J. Payá; M. V. Borrachero A. Córcoles, «Use of sewage sludge ash (SSA)-cement admixtures in mortars». Cement and Concrete Research, 26, 1996. p. 1389-1398.

[13] S. Donatello; M. Tyrer C. R. Cheeseman, « Comparison of test methods to assess pozzolanic activity ». Cement and Concrete Composites, 32, 2010. p. 121-127.

[14] N. Husillos Rodríguez; S. Martínez-Ramírez; M. T. BlancoVarela; S. Donatello; M. Guillem; J. Puig; C. Fos; E. Larrotcha J. Flores, « The effect of using thermally dried sewage sludge as an alternative fuel on Portland cement clinker production ». Journal of Cleaner Production, 52, 2013. p. 94-102.

[15] S.-C. Pan; D.-H. Tseng; C.-C. Lee C. Lee,« Influence of the fineness of sewage sludge ash on the mortar properties $»$. Cement and Concrete Research, 33, 2003. p. 1749-1754.

[16] W. Piasta, M. Lukawska, «The Effect of Sewage Sludge Ash on Properties of Cement Composites». Procedia Engineering, 161, 2016. p. 1018-1024.

[17] M. Cyr; M. Coutand P. Clastres, « Technological and environmental behavior of sewage sludge ash (SSA) in cement-based materials». Cement and Concrete Research, 37, 2007. p. $1278-1289$.
[18] S. Donatello, C. R. Cheeseman, «Recycling and recovery routes for incinerated sewage sludge ash (ISSA): a review ». Waste Manag, 33, 2013. p. 2328-40.

[19] J.-H. Tay, K.-Y. Show, «Municipal wastewater sludge as cementitious and blended cement materials». Cement and Concrete Composites, 16, 1994. p. 39-48.

[20] S. Pan, «Use of sewage sludge ash as fine aggregate and pozzolan in portland cement mortar». Journal of Solid Waste Technology and Management, 28, 2002. p. 121-130.

[21] P. J. Potts; O. Williams-Thorpe P. C. Webb, «The Bulk Analysis of Silicate Rocks by Portable X-Ray Fluorescence: Effect of Sample Mineralogy in Relation to the Size of the Excited Volume». Geostandards and Geoanalytical Research, 21, 1997. p. 29-41.

[22] R. Rajamma; R. J. Ball; L. A. Tarelho; G. C. Allen; J. A. Labrincha V. M. Ferreira, "Characterisation and use of biomass fly ash in cement-based materials». J Hazard Mater, 172, 2009. p. 1049-60.

[23] V. S. Somerset; L. F. Petrik; R. A. White; M. J. Klink; D. Key E. Iwuoha, «The use of X-ray fluorescence (XRF) analysis in predicting the alkaline hydrothermal conversion of fly ash precipitates into zeolites ». Talanta, 64, 2004. p. 109-14.

[24] M. Quintin; C. Riandey; A. M. Kersabiec M. Pinta, «Effets de matrice comparés dans l'analyse des silicates par spectrométrie d'émission d'absorption atomique et de fluorescence X». Analusis, 2, 1973. p. 516-531.

[25] A. Traore; P. M. Ndiaye; M. Mbaye; F. Diatta A. Wague, «XRay Fluorescence Combined with Chemometrics for the Characterization of Geological Samples: A Case Study in Southeastern Senegal». Instrumentation Science \& Technology, 42, 2014. p. 593-604.

[26] S. C. Chin; D. Ing; A. Kusbiantoro; Y. K. Wong S. W. Ahmad, "Characterization of sewage sludge ASH (SSA) in cement mortar ». ARPN J. Eng. Appl. Sci, 11, 2016. p. 2242-2247.

[27] K. Boukheddaden; M. H. Ritti; G. Bouchez; M. Sy; M. M. Dîrtu; M. Parlier; J. Linares Y. Garcia, «Quantitative Contact Pressure Sensor Based on Spin Crossover Mechanism for Civil Security Applications». J. Phys. Chem. C, 122, 2018. p. 7597-7604.

[28] N. S. Pesika; K. J. Stebe P. C. Searson, «Relationship between Absorbance Spectra and Particle Size Distributions for Quantum-Sized Nanocrystals». J. Phys. Chem. B, 107, 2003. p. 10412-10415.

[29] J. Doak; R. K. Gupta; K. Manivannan; K. Ghosh P. K. Kahol, «Effect of particle size distributions on absorbance spectra of gold nanoparticles». Physica E: Low-dimensional Systems and Nanostructures, 42, 2010. p. 1605-1609. 